ARTICLE

Received 17 Nov 2015 | Accepted 26 Feb 2016 | Published 5 Apr 2016

DOI: $10.1038 /$ ncomms11203

OPEN

\title{
Balancing surface adsorption and diffusion of lithium-polysulfides on nonconductive oxides for lithium-sulfur battery design
}

Xinyong Tao ${ }^{1,2}{ }^{\star}$, Jianguo Wang ${ }^{3, \star}$, Chong Liu² ${ }^{2}$ Haotian Wang ${ }^{2}$, Hongbin Yao ${ }^{2}$, Guangyuan Zheng ${ }^{2}$, Zhi Wei Seh ${ }^{2}$, Qiuxia Cai ${ }^{3}$, Weiyang $\mathrm{Li}^{2}$, Guangmin Zhou ${ }^{2}$, Chenxi $\mathrm{Zu}^{2} \& \mathrm{Yi} \mathrm{Cui}^{2,4}$

Lithium-sulfur batteries have attracted attention due to their six-fold specific energy compared with conventional lithium-ion batteries. Dissolution of lithium polysulfides, volume expansion of sulfur and uncontrollable deposition of lithium sulfide are three of the main challenges for this technology. State-of-the-art sulfur cathodes based on metal-oxide nanostructures can suppress the shuttle-effect and enable controlled lithium sulfide deposition. However, a clear mechanistic understanding and corresponding selection criteria for the oxides are still lacking. Herein, various nonconductive metal-oxide nanoparticledecorated carbon flakes are synthesized via a facile biotemplating method. The cathodes based on magnesium oxide, cerium oxide and lanthanum oxide show enhanced cycling performance. Adsorption experiments and theoretical calculations reveal that polysulfide capture by the oxides is via monolayered chemisorption. Moreover, we show that better surface diffusion leads to higher deposition efficiency of sulfide species on electrodes. Hence, oxide selection is proposed to balance optimization between sulfide-adsorption and diffusion on the oxides.

\footnotetext{
${ }^{1}$ College of Materials Science and Engineering, Zhejiang University of Technology, Hangzhou 310014, China. ${ }^{2}$ Department of Materials Science and Engineering, Stanford University, Stanford, California 94305, USA. ${ }^{3}$ College of Chemical Engineering, Zhejiang University of Technology, Hangzhou 310014 China. ${ }^{4}$ Stanford Institute for Materials and Energy Science, SLAC National Accelerator Laboratory, Menlo Park, California 94025, USA. * These authors contributed equally to this work. Correspondence and requests for materials should be addressed to Y.C. (email: yicui@stanford.edu).
} 
R echargeable lithium-sulfur (Li-S) batteries have recently become one of the more exciting energy storage systems due to the low-cost and high-specific energy of sulfur cathodes $^{1-27}$. Although there have been significant developments for designing state-of-the-art Li-S batteries in the past two decades, the practical application is still hindered by many material challenges, including dissolution of intermediate lithium polysulfides $\left(\mathrm{Li}_{2} \mathrm{~S}_{x}, x>3\right)$ in the electrolyte ${ }^{28}$, large volumetric expansion (80\%) of sulfur upon lithiation ${ }^{6}$, and poor electronic/ ionic conductivity of sulfur and lithium sulfide $\left(\mathrm{Li}_{2} \mathrm{~S}\right)$ (ref. 6). To date, tremendous efforts have been made to solve the above problems by constructing advanced composite cathode materials. One effective strategy is the encapsulation of sulfur to prevent the leakage of active materials and suppress the shuttle effect of highorder $\mathrm{Li}_{2} \mathrm{~S}_{x}$ (refs 3,6). Oxides ${ }^{6}$, carbon ${ }^{3,29}$, polymers ${ }^{30}$ and metals ${ }^{31}$ are proved to be good matrix materials for the encapsulation of sulfur ${ }^{19}$. The second approach is the controllable deposition of the discharge product $\mathrm{Li}_{2} \mathrm{~S}$, which is an ionic and electronic insulator ${ }^{4}$. The detaching and irreversible phase transformation of $\mathrm{Li}_{2} \mathrm{~S}$ is considered as the main reason for capacity fading ${ }^{4,32}$. The third strategy is using $\mathrm{Li}_{2} \mathrm{~S}$ as a starting cathode material, which undergoes volumetric contraction instead of the expansion in the case of sulfur ${ }^{20}$. In addition, $\mathrm{Li}_{2} \mathrm{~S}$-based cathodes can be paired with lithium metal-free anodes such as graphite, silicon and alloys ${ }^{33}$, thus suppressing the dendrite growth and the corresponding safety concerns of lithium-metal anodes.

All the previous research reveals the importance of understanding the sulfide species interaction with the matrix materials. Our earlier work pointed out that the usual carbon substrates interact with $\mathrm{Li}_{2} \mathrm{~S}_{x}$ weakly but the polar group enabled strong interaction with $\mathrm{Li}_{2} \mathrm{~S}_{x}$, which can facilitate the $\mathrm{Li}_{2} \mathrm{~S}_{x}$ trapping and promote the attachment of solid $\mathrm{Li}_{2} \mathrm{~S}_{2}$ and $\mathrm{Li}_{2} \mathrm{~S}$ and improve the cycling stability of Li-S batteries ${ }^{24}$. Many similar examples followed-up using polymers ${ }^{35,36}$, oxides ${ }^{4,19}$, sulfides ${ }^{20}$, functionalized graphene $\mathrm{e}^{18,26,27,37,38}$, metal organic framework ${ }^{39}$ and nitrogen doped carbon ${ }^{36,40}$, which all have polar surfaces to adsorb $\mathrm{Li}_{2} \mathrm{~S}_{x}$ species. Results from this study seem to suggest that the stronger the binding, the better the $\mathrm{Li}-\mathrm{S}$ batteries. In addition, it was recognized that using conducting materials such as indium tin oxide ${ }^{4}$ and $\mathrm{Ti}_{4} \mathrm{O}_{7}$ (ref. 19) is preferable due to the electron transfer needed to induce electrochemical reaction. Our recent work showed that indium tin oxide decorated carbon nanofibres can enhance the redox kinetics of $\mathrm{Li}_{2} \mathrm{~S}_{x}$, realize the controllable deposition of $\mathrm{Li}_{2} \mathrm{~S}$ and improve the electrochemical performance of Li-S batteries ${ }^{4}$.

Besides the conductive matrix material, there are indeed abundant insulating materials to trap $\mathrm{Li}_{2} \mathrm{~S}_{x}$. But there is a fundamental problem here: insulated materials cannot transport electrons. Trapping $\mathrm{Li}_{2} \mathrm{~S}_{x}$ on insulating materials would cause them to be accumulated in electronically inactive areas and reduce the capacity retention. However, some studies have shown improvements of the electrochemical properties after the decoration of the electrode with poor conductive oxides such as $\mathrm{MnO}_{2}$ (ref. 16), $\mathrm{Mg}_{0.6} \mathrm{Ni}_{0.4} \mathrm{O}$ (ref. 12), $\mathrm{Al}_{2} \mathrm{O}_{3}$ (ref. 41) and $\mathrm{La}_{2} \mathrm{O}_{3}$ (ref. 42).

The above background research has motivated us to hypothesize that surface diffusion of $\mathrm{Li}_{2} \mathrm{~S}_{x}$ species on solid substrates can play an important role in Li-S battery electrochemical performance. This is particularly important for insulating solid materials with strong adsorption of $\mathrm{Li}_{2} \mathrm{~S}_{x}$. The competition between the adsorption and diffusion of the $\mathrm{Li}_{2} \mathrm{~S}_{x}$ adsorbates on solid substrates can be very important, yet has been overlooked for Li-S batteries.

Usually, the nonconductive metal oxides work together with the carbon matrix to improve the conductivity of sulfur cathodes. For the modified carbon matrix with some nonconductive metal oxides nanostructures (Fig. 1), there is no direct electron transfer between these oxides and $\mathrm{Li}_{2} \mathrm{~S}_{x}$ species. Because of the poor conductivity of the metal oxide, the absorbed $\mathrm{Li}_{2} \mathrm{~S}_{x}$ should be transferred from the surface of the oxide to the conductive carbon substrate to undergo the electrochemical reaction. Therefore the competitive surface diffusion and adsorption of sulfur species must play key roles in the Li-S batteries. If the metal oxide has weak $\mathrm{Li}_{2} \mathrm{~S}_{x}$ capture capability (Fig. 1a), a large amount of $\mathrm{Li}_{2} \mathrm{~S}_{x}$ can diffuse away from the carbon matrix, resulting in serious shuttle effect and uncontrollable deposition of $\mathrm{Li}_{2} \mathrm{~S}$. When the diffusion of sulfur species from the surface of oxide to carbon is difficult (Fig. 1c), the electrochemical reaction of $\mathrm{Li}_{2} \mathrm{~S}_{x}$ and the corresponding growth of $\mathrm{Li}_{2} \mathrm{~S}$ on the oxide/carbon is impeded. Therefore, the balance optimization between $\mathrm{Li}_{2} \mathrm{~S}_{x}$ adsorption and diffusion on the metal oxides surface is necessary (Fig. 1b).

In this work, various nonconductive metal oxide $\left(\mathrm{MgO}, \mathrm{Al}_{2} \mathrm{O}_{3}\right.$, $\mathrm{CeO}_{2}, \mathrm{La}_{2} \mathrm{O}_{3}$ and $\mathrm{CaO}$ ) nanoparticles-decorated carbon flakes are synthesized via a facile and generic biotemplating method using Kapok trees fibres as both the template and the carbon source. The sulfur cathodes based on $\mathrm{MgO}, \mathrm{CeO}_{2}$ and $\mathrm{La}_{2} \mathrm{O}_{3}$ show higher capacity and better cycling stability. Adsorption test, microstructure analysis and electrochemical performance evaluation combined with density functional theory (DFT) calculations reveal that better surface diffusion leads to higher deposition efficiency of sulfide species. A comprehensiveoxide-selection criteria referring to the strong binding, high surface area and good surface diffusion properties is proposed.

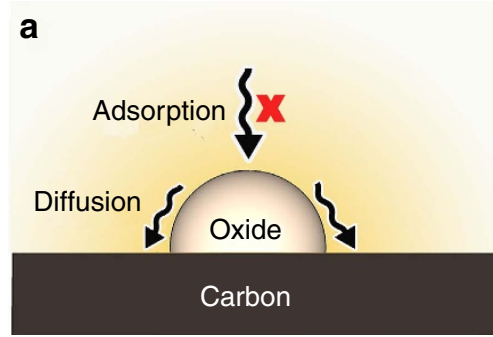

b

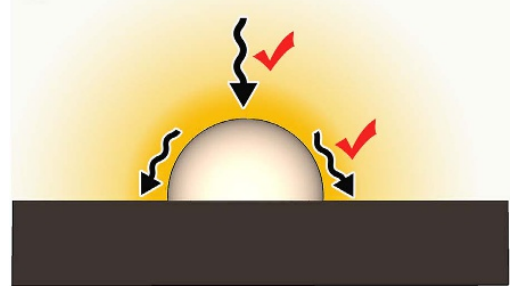

C

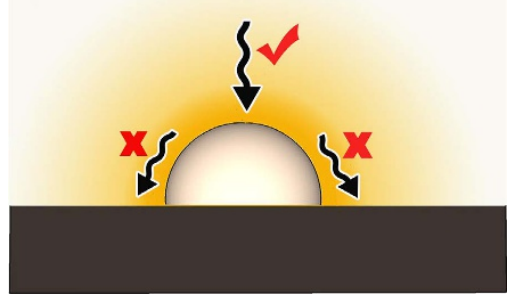

Figure 1 | Schematic of the $\mathrm{Li}_{2} \mathrm{~S}_{\mathrm{x}}$ adsorption and diffusion on the surface of various nonconductive metal oxides. (a) The metal oxide with weak $\mathrm{Li}_{2} \mathrm{~S}_{x}$ adsorption capability; only few $\mathrm{Li}_{2} \mathrm{~S}_{x}$ can be captured by the oxide; (b) the metal oxide with both strong adsorption and good diffusion, which is favourable for the electrochemical reaction and the controllable deposition of sulfur species; (c) the metal oxide with strong bonding but without good diffusion; the growth of $\mathrm{Li}_{2} \mathrm{~S}$ and the electrochemical reaction on the oxide/ C surface is impeded. 


\section{Results}

Sulfide capture by metal oxides. To reveal the role of metal oxides in Li-S batteries, five kinds of pure metal oxidenanoparticles were prepared by a generic Pechini sol-gel $\operatorname{method}^{13}$. 1,3-dioxolane (DOL) and dimethoxyethane (DME) are commonly used solvent in the $\mathrm{Li}-\mathrm{S}$ battery electrolyte ${ }^{4}$. Therefore, $0.005 \mathrm{M} \mathrm{Li}_{2} \mathrm{~S}_{8}$ in DOL/DME $(1: 1, \mathrm{v}-\mathrm{v})$ was prepared for the adsorption test of sulfides. Figure $2 \mathrm{a}$ shows the camera image of the adsorption test using different mass of oxide samples with the same total surface area. The colour of the solution containing $\mathrm{Al}_{2} \mathrm{O}_{3}$ and $\mathrm{CeO}_{2}$ is lighter than the others, indicating better adsorption of these two metal oxide nanoparticles. Inductively coupled plasma-optical emission spectroscopy (ICP-OES) results reveal that $\mathrm{Al}_{2} \mathrm{O}_{3}$ and $\mathrm{CaO}$ show the biggest and the smallest absorption capability, respectively (Fig. 2b). In addition, it was found that the adsorption capacity increases slightly with the rise of temperature (Fig. $2 \mathrm{~b}$ and Supplementary Table 1), which is one essential characteristic of chemisorption. The measured $\mathrm{Li}_{2} \mathrm{~S}_{8}$ adsorption quantity of metal oxides is in the range of $2.78-4.94 \mu \mathrm{mol} \mathrm{m}^{-2}$, close to the simulated monolayer adsorption capacity ranging from 2.76 to $4.88 \mu \mathrm{mol} \mathrm{m}^{-2}$ (Fig. 2b). Therefore, the $\mathrm{Li}_{2} \mathrm{~S}_{8}$ capture involves monolayer adsorption, which is another well-known characteristic of chemisorption.

In order to better understand the absorption mechanism, DFT calculation was performed to reveal the corresponding adsorption energy and sites (Fig. 2c,d and Supplementary Figs 2-6). Considering both low-order and high-order, $\mathrm{Li}_{2} \mathrm{~S}_{x}$ are important discharge products of $\mathrm{Li}-\mathrm{S}$ batteries, we choose both $\mathrm{Li}_{2} \mathrm{~S}$ and $\mathrm{Li}_{2} \mathrm{~S}_{8}$ as the prototype for modelling. Figure 2c shows the optimized geometries of the most stable $\mathrm{Li}_{2} \mathrm{~S}$ on $\mathrm{CeO}_{2}(111)$, $\mathrm{Al}_{2} \mathrm{O}_{3}(110), \mathrm{La}_{2} \mathrm{O}_{3}(001), \mathrm{MgO}(100)$ and $\mathrm{CaO}(100)$ surfaces. On the entire surface, the most favourable binding site of $\mathrm{Li}_{2} \mathrm{~S}$ is two $\mathrm{Li}$ atoms bonding with the oxygen atom of metal oxide (Fig. 2c). On $\mathrm{Al}_{2} \mathrm{O}_{3}(110)$, the $\mathrm{Li}$ of $\mathrm{Li}_{2} \mathrm{~S}$ is the bridge site of two oxygen atoms, on other four metal oxides, the $\mathrm{Li}$ is on the atop site of oxygen. On $\mathrm{MgO}(100) \mathrm{CaO}(100)$ and $\mathrm{La}_{2} \mathrm{O}_{3}(001)$ surfaces, the sulfur of $\mathrm{Li}_{2} \mathrm{~S}$ is away from the metal oxides surface. Sulfur is bonding with oxygen on $\mathrm{CeO}_{2}(111)$, in which the sulfur-oxygen distance is $1.70 \AA$ while with $\mathrm{Al}$ on $\mathrm{Al}_{2} \mathrm{O}_{3}(110)$, in which the $\mathrm{Al}-\mathrm{S}$ distance is $2.21 \AA$. The adsorption energy of $\mathrm{Li}_{2} \mathrm{~S}$ on $\mathrm{CeO}_{2}(111)$, $\mathrm{Al}_{2} \mathrm{O}_{3}(110), \mathrm{La}_{2} \mathrm{O}_{3}(001), \mathrm{MgO}(100)$ and $\mathrm{CaO}(100)$ surfaces is $-6.33,-7.12,-0.5 .85,-5.71$ and $-5.49 \mathrm{eV}$, respectively. The optimized stable configurations of $\mathrm{Li}_{2} \mathrm{~S}_{8}$ on five different surfaces are also shown in Fig. 2d and Supplementary Figs 2-6. Although the $\mathrm{Li}$ of $\mathrm{Li}_{2} \mathrm{~S}_{8}$ has similar bonding sites on the metal oxide surface as that of $\mathrm{Li}_{2} \mathrm{~S}$, the optimized most stable configuration of $\mathrm{Li}_{2} \mathrm{~S}_{8}$ on each metal oxide is quite different. A lot of initial geometries of $\mathrm{Li}_{2} \mathrm{~S}_{8}$ on each metal oxide have been considered in our calculations. It is found that after optimization, the structures have big change due to the interaction between $\mathrm{Li}_{2} \mathrm{~S}_{8}$ and metal oxides. For both $\mathrm{Li}_{2} \mathrm{~S}$ and $\mathrm{Li}_{2} \mathrm{~S}_{8}$ on metal oxides, the bonding between $\mathrm{Li}$ and oxygen plays a major role. In addition, only two or three sulfur atoms of $\mathrm{Li}_{2} \mathrm{~S}_{8}$ are bonding with the oxide surface. The adsorption energies of $\mathrm{Li}_{2} \mathrm{~S}_{8}$ have similar trend on these metal surfaces with $\mathrm{Li}_{2} \mathrm{~S}$, while are much weaker than $\mathrm{Li}_{2} \mathrm{~S}$. The calculated adsorption energies of both $\mathrm{Li}_{2} \mathrm{~S}$ and $\mathrm{Li}_{2} \mathrm{~S}_{8}$ are in agreement with the experimental adsorption test results of $\mathrm{Li}_{2} \mathrm{~S}_{8}$ on the oxide nanoparticles (Fig. $2 \mathrm{~b}$ and Supplementary Table 1).

Biotemplated fabrication of oxides/carbon nanostructures. Although most of these oxides have remarkable adsorption behaviour for sulfide species, they are poor electronic conductors. Conductivity is one of the most important factors affecting the performance of $\mathrm{Li}-\mathrm{S}$ batteries. Therefore, we fabricated metal-oxides $\left(\mathrm{MgO}, \mathrm{Al}_{2} \mathrm{O}_{3}, \mathrm{CeO}_{2}, \mathrm{La}_{2} \mathrm{O}_{3}\right.$ and $\left.\mathrm{CaO}\right)$ nanoparticles anchored on porous carbon nanoflakes to form an electronic conductive oxide/carbon nanocomposite. To fabricate the nanocomposite, Kapok fibres (KFs) ${ }^{43}$ were used as both the template and the carbon source (Fig. 3a). KFs are low-cost and high-yield agriculture products derived from the fruits of Kapok tree, which is chemically composed of $64 \%$ cellulose, $13 \%$ lignin and $23 \%$ pentosan $^{43}$. In addition, the KFs have unique hollow a

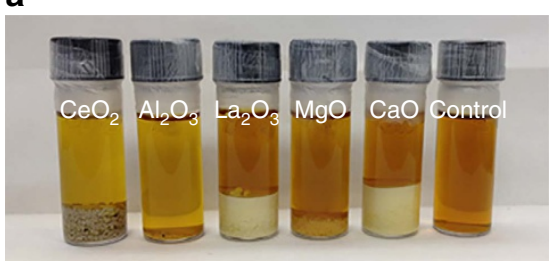

b

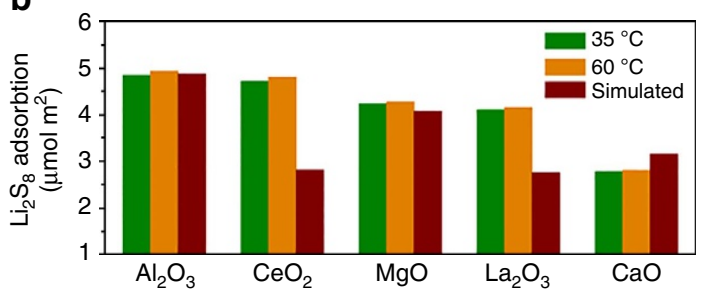

C

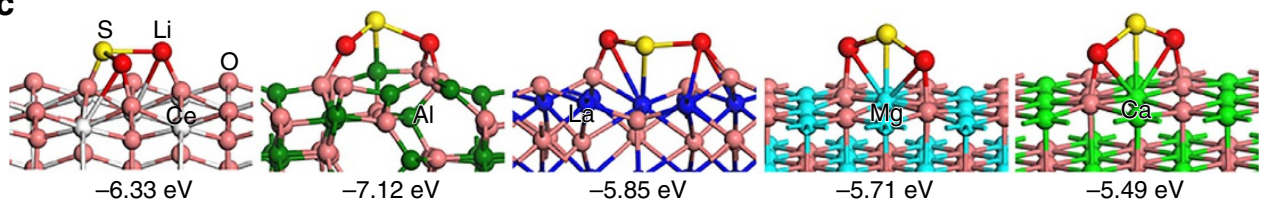

d

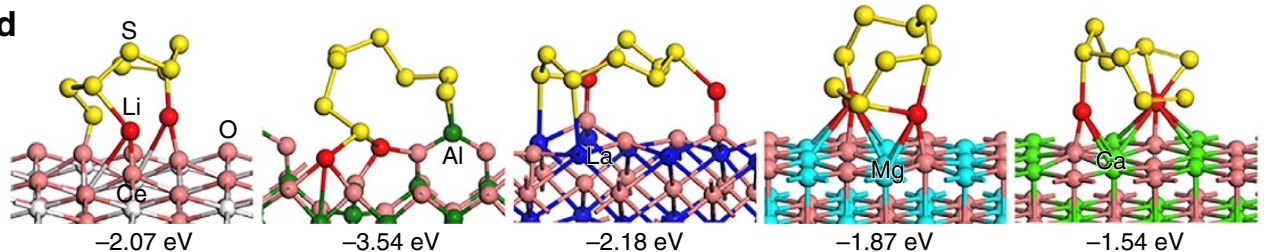

Figure 2 | Adsorption test and relative models of sulfide species on the surface of metal oxides. (a) Digital images of the $\mathrm{Li}_{2} \mathrm{~S}_{8}$ trapping by the metal oxide nanoparticles in DOL/DME $(1: 1, \mathrm{v}-\mathrm{v})$ solution. (b) Experimental and simulated adsorption amount of $\mathrm{Li}_{2} \mathrm{~S}_{8}$ on different metal oxides. The simulated adsorption was based on the monolayer adsorption model. (c) Optimized geometries of the most stable $\mathrm{Li}_{2} \mathrm{~S}$ on $\mathrm{CeO}_{2}(111), \mathrm{Al}_{2} \mathrm{O}_{3}(110), \mathrm{La}_{2} \mathrm{O}_{3}(001)$, $\mathrm{MgO}(100)$ and $\mathrm{CaO}(100)$ surfaces. (d) Optimized geometries of most stable $\mathrm{Li}_{2} \mathrm{~S}_{8}$ on the metal oxide surface. 
a
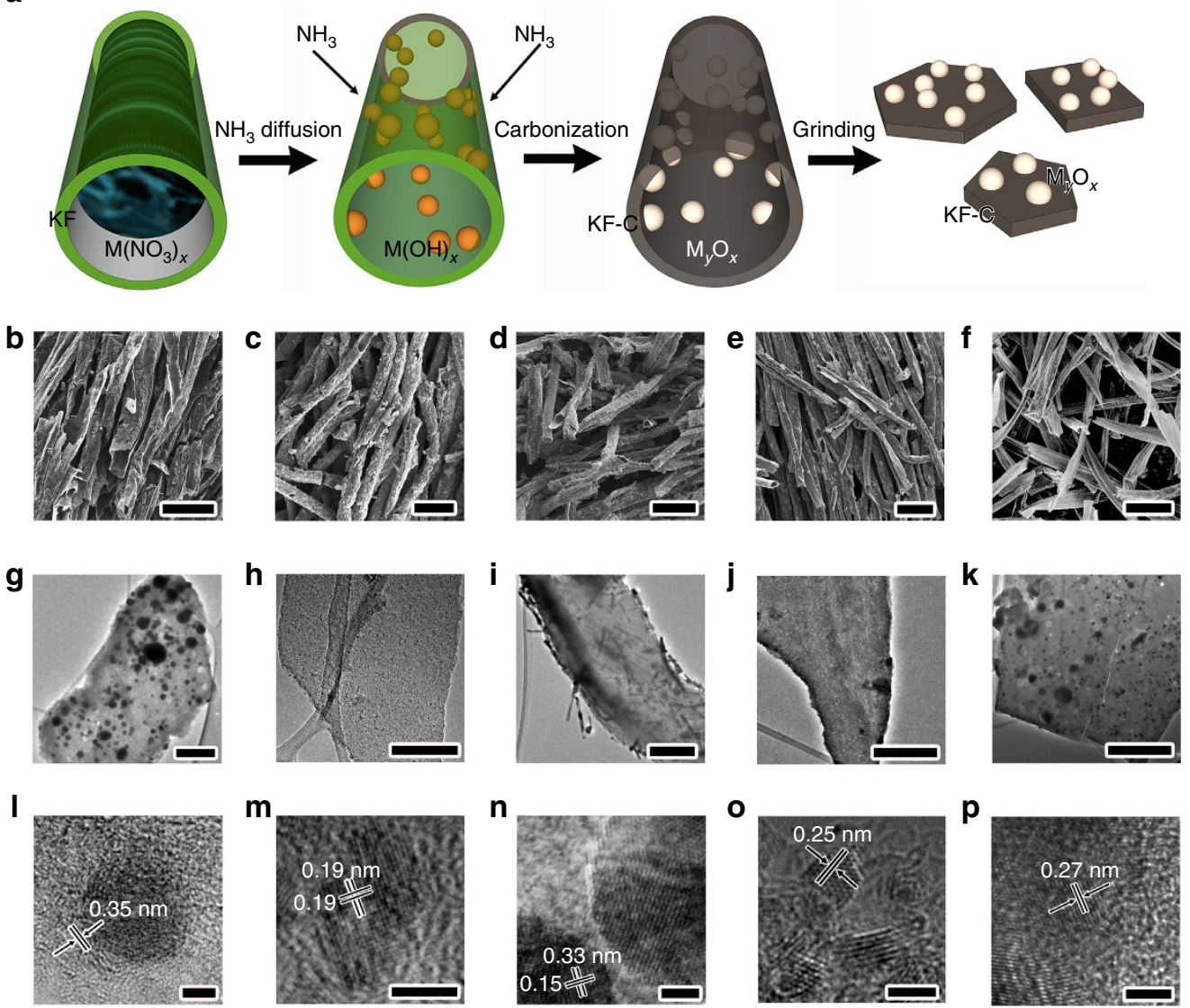

Figure 3 | Fabrication and microstructures of oxides/carbon nanostructures. (a) Schematic illustration of synthesis of oxides/carbon using the kapok tree fibres (KF) as both template and carbon sources. (b-f) SEM images of $\mathrm{Al}_{2} \mathrm{O}_{3} / \mathrm{C}, \mathrm{CeO}_{2} / \mathrm{C}, \mathrm{La}_{2} \mathrm{O}_{3} / \mathrm{C}, \mathrm{MgO} / \mathrm{C}$ and $\mathrm{CaO} / \mathrm{C}$ composites, respectively (scale bar $=50 \mu \mathrm{m})$. (g-k) The corresponding TEM images of $\mathrm{Al}_{2} \mathrm{O}_{3} / \mathrm{C}, \mathrm{CeO}_{2} / \mathrm{C}, \mathrm{La}_{2} \mathrm{O}_{3} / \mathrm{C}, \mathrm{MgO} / \mathrm{C}$ and $\mathrm{CaO} / \mathrm{C}$, respectively (scale bar $=300 \mathrm{~nm}$ ).

(I-p) The corresponding HRTEM images of $\mathrm{Al}_{2} \mathrm{O}_{3} / \mathrm{C}, \mathrm{CeO}_{2} / \mathrm{C}, \mathrm{La}_{2} \mathrm{O}_{3} / \mathrm{C}, \mathrm{MgO} / \mathrm{C}$ and $\mathrm{CaO} / \mathrm{C}$, respectively (scale bar $=3 \mathrm{~nm}$ ).

lumens with a thin wall thickness $\leq 1 \mu \mathrm{m}$, which enables good sorption capacity through capillary force. Therefore, metal nitrate solution can be easily absorbed into the KFs (Fig. 3a). When the $\mathrm{NH}_{3}$ gas diffuses into the KFs through the porous cell wall and the open end, metal hydroxides nanoparticles will be formed on the surface of the cell wall due to the confinement effect of KF template. After drying at $90^{\circ} \mathrm{C}$ for $12 \mathrm{~h}$, carbonization at $850^{\circ} \mathrm{C}$ for $1.5 \mathrm{~h}$ and the following facile grinding, carbon nanoflakes decorated with metal oxide nanoparticles can be obtained (Fig. 3a). Figure $3 \mathrm{~b}-\mathrm{f}$ shows the scanning electron microscopy (SEM) images of $\mathrm{Al}_{2} \mathrm{O}_{3} / \mathrm{C}, \mathrm{CeO}_{2} / \mathrm{C}, \mathrm{La}_{2} \mathrm{O}_{3} / \mathrm{C}, \mathrm{MgO} / \mathrm{C}$ and $\mathrm{CaO} / \mathrm{C}$ nanocomposites, respectively. The composite remains the macromorphology of the original Kapok tree fibres, which have a unique hollow structure with a large lumen and a thin fibre wall. After simple grinding, the delicate carbon microtubes are converted to carbon nanoflakes (Fig. $3 \mathrm{~g}-\mathrm{k}$ and Supplementary Figs 7-9).

Moreover, transmission electron microscopy (TEM) images show that abundant oxide nanostructures are located on the carbon matrix (Fig. 3g-k). Figure 31 is the representative high resolution TEM (HRTEM) image of the $\mathrm{Al}_{2} \mathrm{O}_{3} / \mathrm{C}$ sample, showing the amorphous structure of $\mathrm{Al}_{2} \mathrm{O}_{3}$ and partially graphitized structure of $\mathrm{C}$. The interlayer spacing is about $0.35 \mathrm{~nm}$, corresponding to (002) planes of graphite. Figure $3 \mathrm{~m}$ shows the [001] zone axis HRTEM image of a typical $\mathrm{CeO}_{2}$ nanoparticle in $\mathrm{CeO}_{2} / \mathrm{C}$ composite. The lattice spacing of $0.19 \mathrm{~nm}$ in Fig. $3 \mathrm{~m}$ can be attributed to $\{220\}$ crystal planes of the face centred cubic (fcc) phase $\mathrm{CeO}_{2}$. The TEM image of $\mathrm{La}_{2} \mathrm{O}_{3} / \mathrm{C}$ is showed in Fig. 3i, suggesting that abundant rod-shaped nanoparticles are distributed in the carbon matrix. The corresponding HRTEM image in Fig. $3 n$ shows that the $\mathrm{La}_{2} \mathrm{O}_{3}$ particle is single crystalline. The lattice spacings $(0.15$ and $0.33 \mathrm{~nm}$ ) and the interplanar angle match the finger print of (004) and (100) planes of hexagonal phase $\mathrm{La}_{2} \mathrm{O}_{3}$. HRTEM image of $\mathrm{MgO} / \mathrm{C}$ sample in Fig. 3o indicates lattice fringes with regular spacing of $0.25 \mathrm{~nm}$, which can be indexed to (111) planes of fcc $\mathrm{MgO}$. Figure $3 \mathrm{p}$ shows the HRTEM image of $\mathrm{CaO} / \mathrm{C}$ sample. The fringes with spacing of $0.27 \mathrm{~nm}$ is corresponding to (111) planes of fcc $\mathrm{CaO}$. These TEM results indicate that the Kapok tree fibre can act as ideal and general template for the synthesis of oxide nanostructures due to the confinement effect of fibre substrate.

Electrochemical performance of composite cathodes. Thermal diffusion method was used to fabricate the sulfur $/ \mathrm{M}_{x} \mathrm{O}_{y} / \mathrm{C}$ composite $^{19}$. The mass loading of the electrode ranges from 0.7 to $1.2 \mathrm{mg} \mathrm{cm}^{-2}$. The electrolyte was $1 \mathrm{M}$ Lithium bis (trifluoromethanesulphonyl)imide in DOL and DME, with $\mathrm{LiNO}_{3}$ as additive to passivate the lithium anode. Figure $4 \mathrm{a}$ shows the representative charge-discharge curves of the composite electrode based on different oxide/carbon nanostructures at a current rate of $0.1 \mathrm{C}\left(1 \mathrm{C}=1,672 \mathrm{~mA} \mathrm{~g}^{-1}\right)$. All the discharge curves show two typical discharge plateaus at 2.35 and $2.10 \mathrm{~V}$, which can be assigned to the formation of high-order and loworder $\mathrm{Li}_{2} \mathrm{~S}_{x}$, respectively ${ }^{9}$. No obvious difference can be found for the potential of the discharge plateaus. However, the $\mathrm{CaO} / \mathrm{C}$ and 

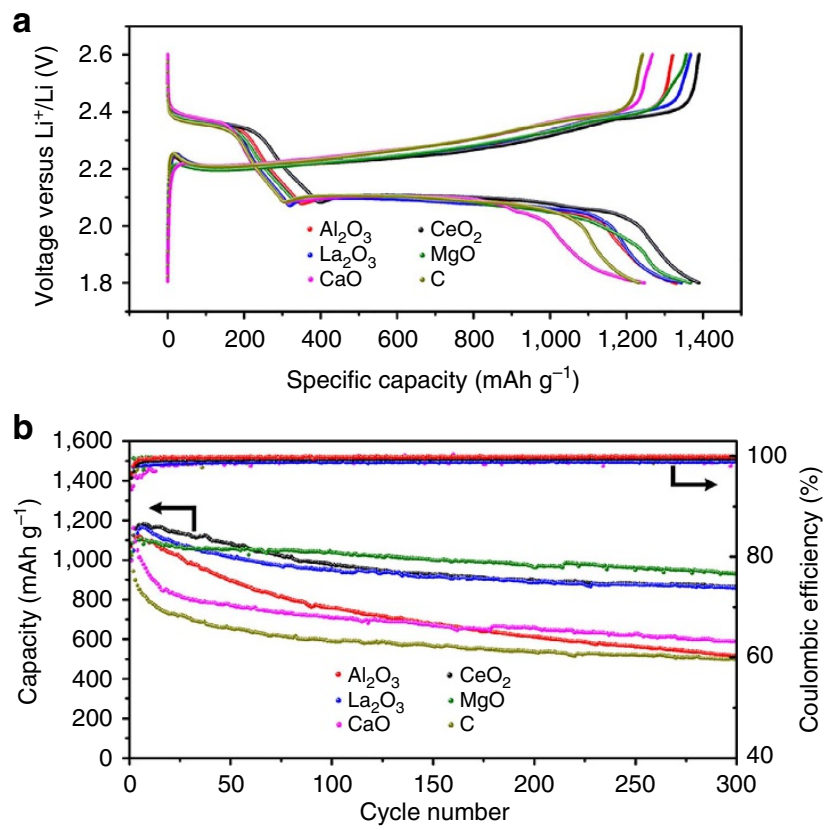

Figure 4 | Charge-discharge curves and cycling performance of the sulfur composite electrodes. (a) Representative charge-discharge profiles of the composite electrodes based on different oxide/carbon nanostructures at $0.1 \mathrm{C}$. (b) Specific capacity and the corresponding Coulombic efficiency of the composite electrodes upon prolonged 300 charge-discharge cycles at $0.5 \mathrm{C}$

$\mathrm{C}$ composite cathodes show higher charge over-potentials than those of $\mathrm{CeO}_{2} / \mathrm{C}, \mathrm{La}_{2} \mathrm{O}_{3} / \mathrm{C}, \mathrm{Al}_{2} \mathrm{O}_{3} / \mathrm{C}$ and $\mathrm{MgO} / \mathrm{C}$ composite electrodes (Fig. 4a). The specific discharge capacities of $\mathrm{Al}_{2} \mathrm{O}_{3} / \mathrm{C}$, $\mathrm{CeO}_{2} / \mathrm{C}, \mathrm{La}_{2} \mathrm{O}_{3} / \mathrm{C}, \mathrm{MgO} / \mathrm{C}, \mathrm{CaO} / \mathrm{C}$ and $\mathrm{C}$ at $0.1 \mathrm{C}$ rate are measured to be $1,330,1,388,1,345,1,368,1,246$ and $1,230 \mathrm{mAhg}^{-1}$, respectively (Fig. 4a). It can be found that the $\mathrm{CaO} / \mathrm{C}$ and $\mathrm{C}$ composite cathodes show relatively lower discharge capacity. The high over-potential and low discharge capacity may result from the serious dissolution of $\mathrm{Li}_{2} \mathrm{~S}_{x}$ in electrolyte (shuttle effect), which causes the active material loss and the increase of electrolyte viscosity. ICP-OES test (Supplementary Table 2) based on the same mass of $\mathrm{Al}_{2} \mathrm{O}_{3} / \mathrm{C}$, $\mathrm{CeO}_{2} / \mathrm{C}, \mathrm{La}_{2} \mathrm{O}_{3} / \mathrm{C}, \mathrm{MgO} / \mathrm{C}, \mathrm{CaO} / \mathrm{C}$ and $\mathrm{C}$ samples reveal that both $\mathrm{CaO} / \mathrm{C}$ and $\mathrm{C}$ have poorer $\mathrm{Li}_{2} \mathrm{~S}_{x}$ capture capability compared with other samples.

Besides the specific capacity, cycling performance is one of the most important characteristics for Li-S batteries. Therefore, all the cathodes were subject to prolonged cycling. Figure $4 \mathrm{~b}$ shows the discharge capacity and the corresponding Coulombic efficiency of the cathodes upon prolonged 300 cycles at $0.5 \mathrm{C}$. The representative charge/discharge curves (Fig. 4a) and the cycling performance (Fig. $4 \mathrm{~b}$ ) indicate that $\mathrm{Al}_{2} \mathrm{O}_{3} / \mathrm{C}, \mathrm{CeO}_{2} / \mathrm{C}$, $\mathrm{La}_{2} \mathrm{O}_{3} / \mathrm{C}$ and $\mathrm{MgO} / \mathrm{C}$ composite electrode show high specific capacity in the first several cycles. However, the composite electrodes show distinct capacity retention capability. The $\mathrm{Al}_{2} \mathrm{O}_{3} / \mathrm{C}, \mathrm{CaO} / \mathrm{C}$ and $\mathrm{C}$ cathodes exhibit obvious capacity fading especially in the first 100 cycles. Compared with $\mathrm{Al}_{2} \mathrm{O}_{3} / \mathrm{C}, \mathrm{CaO} / \mathrm{C}$ and $\mathrm{C}$ cathodes, the electrode based on $\mathrm{CeO}_{2} / \mathrm{C}, \mathrm{La}_{2} \mathrm{O}_{3} / \mathrm{C}$ and $\mathrm{MgO} / \mathrm{C}$ show better cycling performance and the $\mathrm{MgO} / \mathrm{C}$ cathode is the best among all the samples. The capacity decay per cycle is $0.171,0.066,0.047,0.034,0.136$ and $0.170 \%$ for $\mathrm{Al}_{2} \mathrm{O}_{3} / \mathrm{C}, \mathrm{CeO}_{2} / \mathrm{C}$, $\mathrm{La}_{2} \mathrm{O}_{3} / \mathrm{C}, \mathrm{MgO} / \mathrm{C}, \mathrm{CaO} / \mathrm{C}$ and $\mathrm{C}$, respectively. Considering the serious capacity, decay mainly happens in the first 50 cycles, the average Columbic efficiency in the first 100 cycles was calculated (Fig. 4b). $\mathrm{Al}_{2} \mathrm{O}_{3} / \mathrm{C}, \mathrm{CeO}_{2} / \mathrm{C}, \mathrm{La}_{2} \mathrm{O}_{3} / \mathrm{C}, \mathrm{MgO} / \mathrm{C}, \mathrm{CaO} / \mathrm{C}$ and $\mathrm{C}$ cathodes show 99.6, 99.1, 98.7, 99.4, 98.3 and $98.8 \%$ columbic efficiency. Lower Columbic efficiency of Li-S batteries resulted from the significant $\mathrm{Li}_{2} \mathrm{~S}_{x}$ dissolution, which cause the loss of $\mathrm{S}$ material and shuttle effect ${ }^{19}$. This can be also supported by the ICP-OES results, revealing that $\mathrm{Al}_{2} \mathrm{O}_{3} / \mathrm{C}$ has the best capture capability and $\mathrm{CaO} / \mathrm{C}$ and $\mathrm{C}$ have poorer capture capability for $\mathrm{Li}_{2} \mathrm{~S}_{8}$ (Supplementary Table 2). Although $\mathrm{Al}_{2} \mathrm{O}_{3} / \mathrm{C}$ cathodes possess high initial discharge capacity and good Columbic efficiency, the rate of capacity decay is higher than those of $\mathrm{CeO}_{2} / \mathrm{C}, \mathrm{La}_{2} \mathrm{O}_{3} / \mathrm{C}$ and $\mathrm{MgO} / \mathrm{C}$ cathodes. The distinct Columbic efficiency for $\mathrm{Al}_{2} \mathrm{O}_{3}(99.6 \%)$ cathode from both $\mathrm{CaO} / \mathrm{C}$ (98.3\%) and C (98.8\%) cathodes may imply different capacity decay mechanism.

Analysis of capacity failure mechanism of composite cathodes. In order to further reveal the detailed capacity decay mechanism, some batteries were disassembled after 100 cycles at $0.5 \mathrm{C}$ to observe the morphology evolution of the cathode materials by SEM. Figure 5a-f shows low magnification SEM images of the cycled electrodes based on $\mathrm{Al}_{2} \mathrm{O}_{3} / \mathrm{C}, \mathrm{CeO}_{2} / \mathrm{C}, \mathrm{La}_{2} \mathrm{O}_{3} / \mathrm{C}, \mathrm{MgO} / \mathrm{C}$, $\mathrm{CaO} / \mathrm{C}$ and $\mathrm{C}$ nanostructures, respectively. In contrast to $\mathrm{CeO}_{2} / \mathrm{C}$ (Fig. 5b), $\mathrm{La}_{2} \mathrm{O}_{3} / \mathrm{C}$ (Fig. 5c) and $\mathrm{MgO} / \mathrm{C}$ (Fig. 5d) electrodes with uniform and flat surface, the $\mathrm{Al}_{2} \mathrm{O}_{3} / \mathrm{C}$ (Fig. 5a), $\mathrm{CaO} / \mathrm{C}$ (Fig. 5e) and $\mathrm{C}$ (Fig. 5f) cathodes show high surface roughness. Some carbon nanoflakes with well-defined profile can be observed on the surface of the $\mathrm{Al}_{2} \mathrm{O}_{3} / \mathrm{C}$ (Fig. $5 \mathrm{a}$ ), $\mathrm{CaO} / \mathrm{C}$ (Fig. 5e) and $\mathrm{C}$ (Fig. 5f) cathodes after 100 cycles. In addition, some cracks and pinholes can be found in the $\mathrm{CaO} / \mathrm{C}$ and carbon cathodes, which may result from the significant dissolution and loss of sulfur. Figure $5 \mathrm{~g}-1$ and $\mathrm{m}-\mathrm{r}$ shows the top-view and cross-sectional SEM images of cycled $\mathrm{Al}_{2} \mathrm{O}_{3} / \mathrm{C}$, $\mathrm{CeO}_{2} / \mathrm{C}, \mathrm{La}_{2} \mathrm{O}_{3} / \mathrm{C}, \mathrm{MgO} / \mathrm{C}, \mathrm{CaO} / \mathrm{C}$ and $\mathrm{C}$ cathodes, respectively. Only a thin, uniform and dense $\mathrm{Li}_{2} \mathrm{~S}$ film can be found on the surface of $\mathrm{Al}_{2} \mathrm{O}_{3} / \mathrm{C}$ (Fig. 5g,m). Abundant $\mathrm{Li}_{2} \mathrm{~S}$ particles with irregular shape were formed between the $\mathrm{Al}_{2} \mathrm{O}_{3} / \mathrm{C}$ nanoflakes (Supplementary Fig. 1). Similar phenomenon can also be found in the $\mathrm{CaO} / \mathrm{C}$ (Fig. 5k,q) and $\mathrm{C}$ (Fig. 5l,r) cathodes. Some characteristic stripes (Fig. 5k,l) and distinct fracture surface (Fig. 5q,r) indicate that the $\mathrm{Li}_{2} \mathrm{~S}$ particles are detached from the oxides/C matrix and may become electrochemically inactive. This is due to the uncontrollable precipitation of $\mathrm{Li}_{2} \mathrm{~S}$ on the non-polar or weakly polar surface ${ }^{6}$, which leads the further decay of capacity. In contrast, it is not easy to identify the oxide/carbon nanoflakes from the $\mathrm{CeO}_{2} / \mathrm{C}$ (Fig. 5h), $\mathrm{La}_{2} \mathrm{O}_{3} / \mathrm{C}$ (Fig. 5i) and $\mathrm{MgO} / \mathrm{C}$ (Fig. 5j) cathodes. To obtain the cross-sectional morphology of the cathodes, the electrode materials were scraped from the $\mathrm{Al}$ foil current collector and mounted on a copper foil with rough surface for SEM observation. $\mathrm{CeO}_{2} / \mathrm{C}$ (Fig. 5n), $\mathrm{La}_{2} \mathrm{O}_{3} / \mathrm{C}$ (Fig. 5o) and $\mathrm{MgO} / \mathrm{C}$ (Fig. 5p) nanoflakes were wrapped by thick $\mathrm{Li}_{2} \mathrm{~S}$ layer. Supposing that the average thickness of carbon nanoflakers is $450 \mathrm{~nm}$, the thickness of $\mathrm{Li}_{2} \mathrm{~S}$ layer deposited on the surface of $\mathrm{CeO}_{2} / \mathrm{C}, \mathrm{La}_{2} \mathrm{O}_{3} / \mathrm{C}$ and $\mathrm{MgO} / \mathrm{C}$ will be $1,400,1,677$ and $1,573 \mathrm{~nm}$, respectively. After mechanical scrapping and mounting processes, no detachment can be observed, indicating that there is good cohesion between the $\mathrm{Li}_{2} \mathrm{~S}$ layer and the oxide/C nanoflakes. These results are consistent with our DFT calculation results in Fig. 2. Because the $\mathrm{Li}_{2} \mathrm{~S}$ is a poor ionic and electronic conductor, the good combination of $\mathrm{Li}_{2} \mathrm{~S}$ with the conductive matrix must be favourable for the reversible electrochemical reaction in the following charging process ${ }^{4}$. Therefore, the better cycling performance of $\mathrm{CeO}_{2} / \mathrm{C}$, $\mathrm{La}_{2} \mathrm{O}_{3} / \mathrm{C}$ and $\mathrm{MgO} / \mathrm{C}$ cathodes can be attributed to the controllable precipitation of $\mathrm{Li}_{2} \mathrm{~S}$ on the polar surface of carbon matrix. 

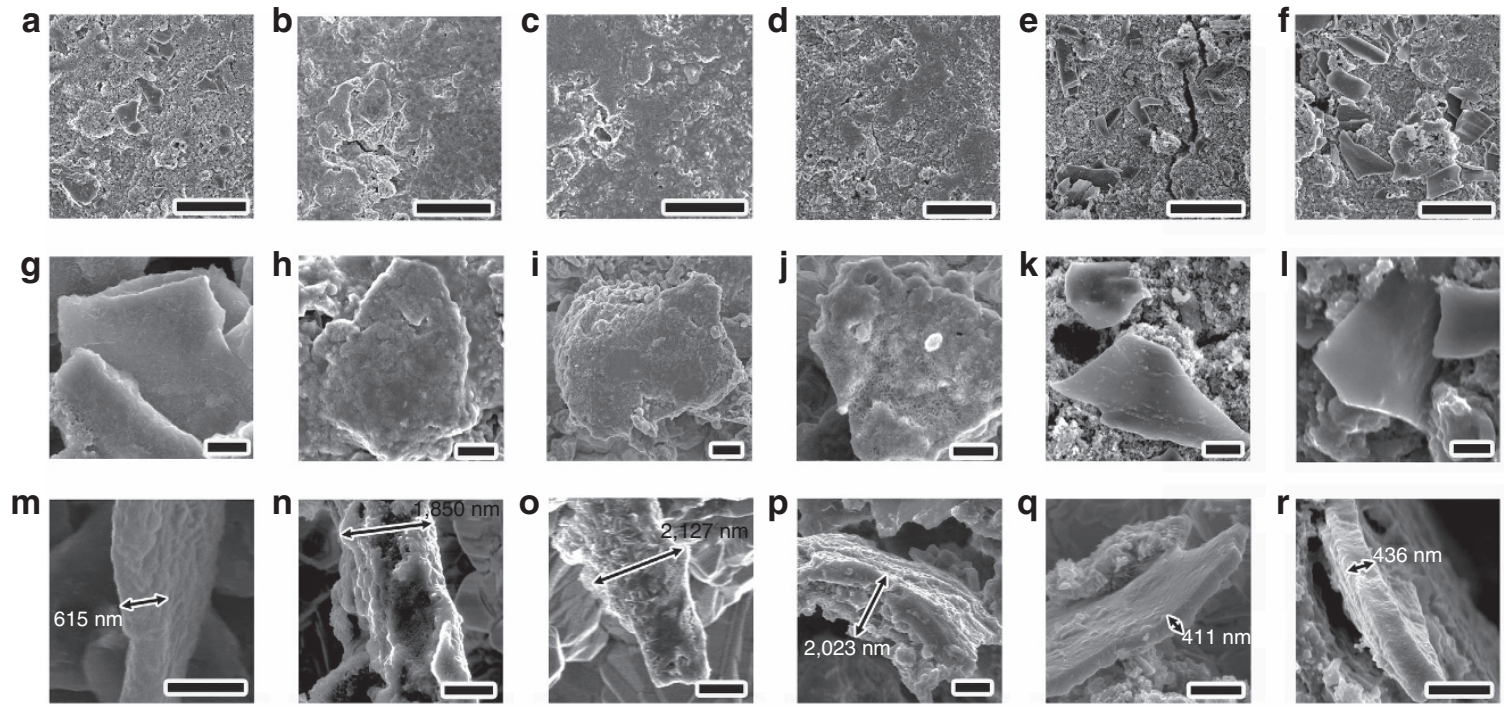

Figure 5 | Morphology of the discharged composite electrodes after cycling. (a-f) SEM images of the cycled composite electrodes based on $\mathrm{Al}_{2} \mathrm{O}_{3} / \mathrm{C}_{1}$ $\mathrm{CeO}_{2} / \mathrm{C}, \mathrm{La}_{2} \mathrm{O}_{3} / \mathrm{C}, \mathrm{MgO} / \mathrm{C}, \mathrm{CaO} / \mathrm{C}$ and carbon nanostructures, respectively. (g-I) Top view and (m-r) cross-sectional SEM images show typical $\mathrm{Al}_{2} \mathrm{O}_{3} / \mathrm{C}$ $\mathrm{CeO}_{2} / \mathrm{C}, \mathrm{La}_{2} \mathrm{O}_{3} / \mathrm{C}, \mathrm{MgO} / \mathrm{C}, \mathrm{CaO} / \mathrm{C}$ and $\mathrm{C}$ nanostructures after cycling, respectively. Scale bars $=10 \mu \mathrm{m}$ (a-f) and $1 \mu \mathrm{m}(\mathbf{g}-\mathbf{r})$.
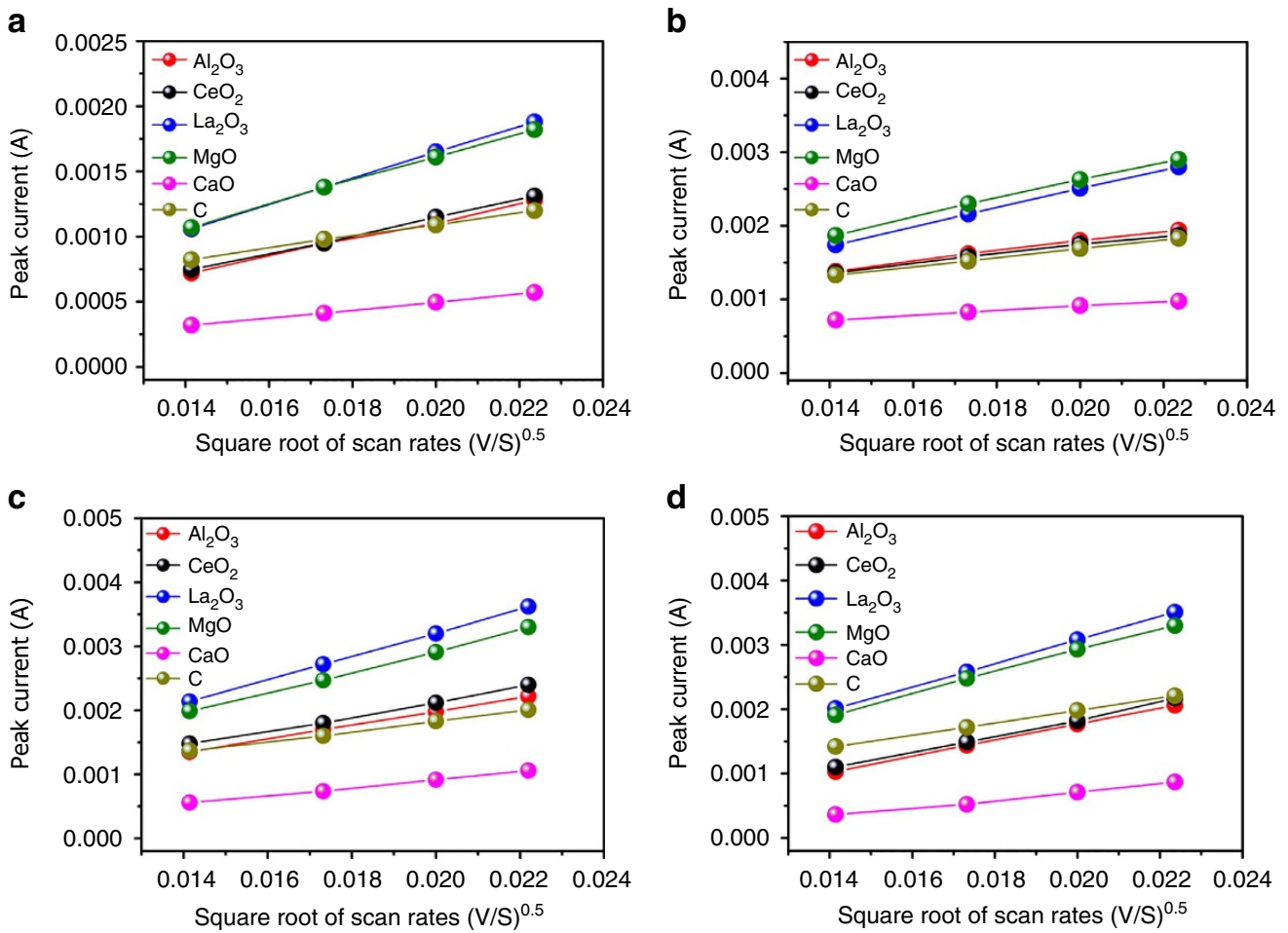

Figure 6 | Lithium ion diffusion properties of the electrode at various voltage scan rates. Plot of CV peak current of (a) the cathodic reaction 1 $\left(\mathrm{S}_{8} \rightarrow \mathrm{Li}_{2} \mathrm{~S}_{4}\right),(\mathbf{b})$ the cathodic reaction $2\left(\mathrm{Li}_{2} \mathrm{~S}_{4} \rightarrow \mathrm{Li}_{2} \mathrm{~S}\right),(\mathbf{c})$ the anodic reaction $1\left(\mathrm{Li}_{2} \mathrm{~S} \rightarrow \mathrm{Li}_{2} \mathrm{~S}_{4}\right)$ and $(\mathbf{d})$ the anodic reaction $2\left(\mathrm{Li}_{2} \mathrm{~S}_{4} \rightarrow \mathrm{S}_{8}\right)$ versus the square root of scan rates.

By now, some important questions arise: why $\mathrm{Li}_{2} \mathrm{~S}$ shows different deposition behaviour on various oxide/C surfaces? Which kind of oxide/C surface is favourable for the controllable precipitation of $\mathrm{Li}_{2} \mathrm{~S}$ ? Because the nucleation and initial growth sites of $\mathrm{Li}_{2} \mathrm{~S}$ are located on the surface of oxide/C, the growth behaviour of $\mathrm{Li}_{2} \mathrm{~S}$ must be related to surface chemical properties of oxide/C matrix. First, the oxide/C surface should absorb highorder $\mathrm{Li}_{2} \mathrm{~S}_{x}$ owing to its strong adsorption ability (Fig. $2 \mathrm{~d}$ ), which acts as the sulfur source for the growth of $\mathrm{Li}_{2} \mathrm{~S}$. The absorbed
$\mathrm{Li}_{2} \mathrm{~S}_{x}$ must be transferred from the oxide surface to conductive carbon surface to enable the electrochemical reactions due to the insulating properties of these metal oxides. Therefore, the distribution and structure of $\mathrm{Li}_{2} \mathrm{~S}$ will be affected by the surface diffusion properties of $\mathrm{Li}_{2} \mathrm{~S}_{x}$ species on the oxide/C substrate.

Lithium ion diffusion properties and mechanism of the cathodes. Although it is very difficult to get the diffusivity of $\mathrm{Li}_{2} \mathrm{~S}_{x}$ on the 
oxide surface from the electrochemical measurement, the lithium diffusivity in the whole Li-S batteries can offer the important information about $\mathrm{Li}_{2} \mathrm{~S}_{x}$ surface diffusion because of that the most favourable binding site of sulfides is two Li atoms bonding with metal oxide (Fig. 2c,d). In order to explore the lithium diffusion properties, we performed cyclic voltammetry $(\mathrm{CV})$ measurements under different scanning rates ranging from 0.2 to $0.5 \mathrm{mV} \mathrm{s}^{-1}$. As shown in Fig. 6, all cathodic and anodic peak currents are linear with the square root of scan rates, from which the lithium diffusion performance can be estimated using the classical Randles Sevcik equation ${ }^{44}$ :

$$
I_{\mathrm{p}}=\left(2.69 \times 10^{5}\right) n^{1.5} a D^{0.5} C v^{0.5} \Delta C_{\mathrm{o}},
$$

where, $I_{\mathrm{p}}$ is the peak current, $n$ is the number of electrons per reaction species, $a$ is the active electrode area, $D$ is the lithium ion diffusion coefficient, $\Delta C_{\mathrm{o}}$ is the $\mathrm{Li}$ concentration change corresponding to the electrochemical reaction. The $n, a$ and $\Delta C_{\mathrm{o}}$ are constant in our battery system. The slopes of curves in Fig. 6a-d are positively correlated to the corresponding lithium ion diffusion, which indicates that the sulfur composite cathode based on both $\mathrm{CaO} / \mathrm{C}$ and $\mathrm{C}$ have lower diffusivity. Abundant high viscosity $\mathrm{Li}_{2} \mathrm{~S}_{x}$ dissolved in the electrolyte and the poor $\mathrm{Li}_{2} \mathrm{~S}_{x}$ capture capability of both $\mathrm{CaO} / \mathrm{C}$ and $\mathrm{C}$ is believed to be the main reason for their low diffusivity. Compared with $\mathrm{CaO} / \mathrm{C}, \mathrm{CeO}_{2} / \mathrm{C}, \mathrm{Al}_{2} \mathrm{O}_{3} / \mathrm{C}$ and $\mathrm{C}$ electrodes, $\mathrm{La}_{2} \mathrm{O}_{3} / \mathrm{C}$ and $\mathrm{MgO} / \mathrm{C}$ samples show better diffusion properties and the measured diffusivity of $\mathrm{Al}_{2} \mathrm{O}_{3} / \mathrm{C}$ cathode is comparable with the $\mathrm{CeO}_{2} / \mathrm{C}$.

The diffusion of lithium on the surface of various metal oxides has been investigated by the DFT calculation (Fig. 7). Because the most favourable binding site of sulfides is two Li atoms bonding with metal oxide (Fig. $2 \mathrm{c}, \mathrm{d}$ ), the calculated Li ion diffusion can also indicate the diffusivity of sulfides species on the surface of the oxide. $\mathrm{On} \mathrm{MgO}(100), \mathrm{CaO}(100)$ and $\mathrm{La}_{2} \mathrm{O}_{3}(001)$ surfaces, the diffusions of $\mathrm{Li}$ in different dimensions can be realized on three equivalent adsorption sites (Fig. 7). Among the three kinds of surfaces, the diffusion barrier of $\mathrm{Li}$ on $\mathrm{CaO}(100)$ is largest. The space group of $\mathrm{MgO}$ is same with $\mathrm{CaO}$, however, the diffusion barrier of $\mathrm{Li}$ on $\mathrm{MgO}(100)$ is about $0.45 \mathrm{eV}$ lower than that on $\mathrm{CaO}(100)$. The suitable adsorption energies of sulfide species and small diffusion barriers of $\mathrm{Li}$ on $\mathrm{MgO}$ will lead to the formation of abundant $\mathrm{Li}_{2} \mathrm{~S}$ particles on $\mathrm{MgO} / \mathrm{C}$ surfaces, which are responsible for the best cycling performance of $\mathrm{MgO} / \mathrm{C}$ cathodes. On $\mathrm{CeO}_{2}(111)$ surfaces, the large diffusion barrier is $0.66 \mathrm{eV}$, which is similar with that on $\mathrm{La}_{2} \mathrm{O}_{3}(001)$ surfaces. This may explain why $\mathrm{CeO}_{2} / \mathrm{C}$ and $\mathrm{La}_{2} \mathrm{O}_{3} / \mathrm{C}$ cathodes show similar cycling performance. Among the five kinds of metal oxides surfaces, the largest diffusion barrier $(1.22 \mathrm{eV})$ of $\mathrm{Li}$ is found to be on $\mathrm{Al}_{2} \mathrm{O}_{3}(110)$, which is about three times of that on $\mathrm{MgO}(100)$. It is seen that sulfide species can strongly adsorb, however, difficult to diffuse on $\mathrm{Al}_{2} \mathrm{O}_{3}$. Although $\mathrm{Al}_{2} \mathrm{O}_{3}$ has the strongest $\mathrm{Li}_{2} \mathrm{~S}_{8}$ adsorption (Fig. 2), the slow diffusion of $\mathrm{Li}_{2} \mathrm{~S}_{x}$ indicated that $\mathrm{Al}_{2} \mathrm{O}_{3}$ may not be a good additive for sulfur cathode.

\section{Discussion}

Based on our experimental results, we clarify three functions of these oxides. The first basic function of these metal oxides is the $\mathrm{Li}_{2} \mathrm{~S}_{x}$ adsorption. Although many literatures have reported the $\mathrm{Li}_{2} \mathrm{~S}_{x}$ capture capacities, the detailed absorption mechanism is still unclear. Our DFT calculation and temperature swing adsorption experiments (Fig. 2) confirm that the monolayer chemisorption is dominant during the $\mathrm{Li}_{2} \mathrm{~S}_{x}$ capture. The second function of these metal oxides, especially some nonconductive oxides, is the $\mathrm{Li}_{2} \mathrm{~S}_{x}$ transfer station, which transports the $\mathrm{Li}_{2} \mathrm{~S}_{x}$ from the poorly conductive oxide surface to high conductive carbon matrix to ensure the full electrochemical conversion. The third function is to induce the controlled growth of $\mathrm{Li}_{2} \mathrm{~S}$ species on the surface of the composite instead of random deposition. Many reports proved that the uncontrolled deposition will result in electrochemically inactive large agglomerations of $\mathrm{Li}_{2} \mathrm{~S}$. The subsequent detachment of $\mathrm{Li}_{2} \mathrm{~S}$ from the oxide/carbon matrix is the main capacity decay mechanism, which can be supported by the SEM observation in Fig. 5. The SEM observations, diffusion test and DFT calculations revealed that the deposition of $\mathrm{Li}_{2} \mathrm{~S}$ on the surface of oxide/carbon matrix may be influenced by the lithium ion diffusion properties on the surface of metal oxides, which has not yet been identified. Surface diffusion properties will affect the distribution and growth of $\mathrm{Li}_{2} \mathrm{~S}$.

Based on these functions of nonconductive metals oxides, we can propose an oxide selection criterion for the Li-S batteries. a

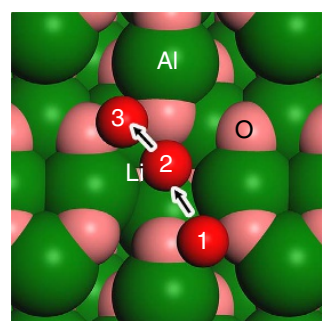

d

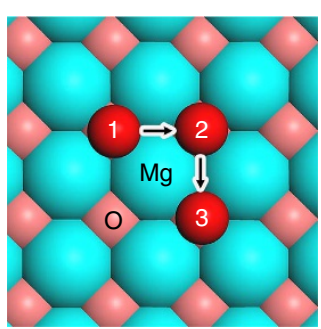

b
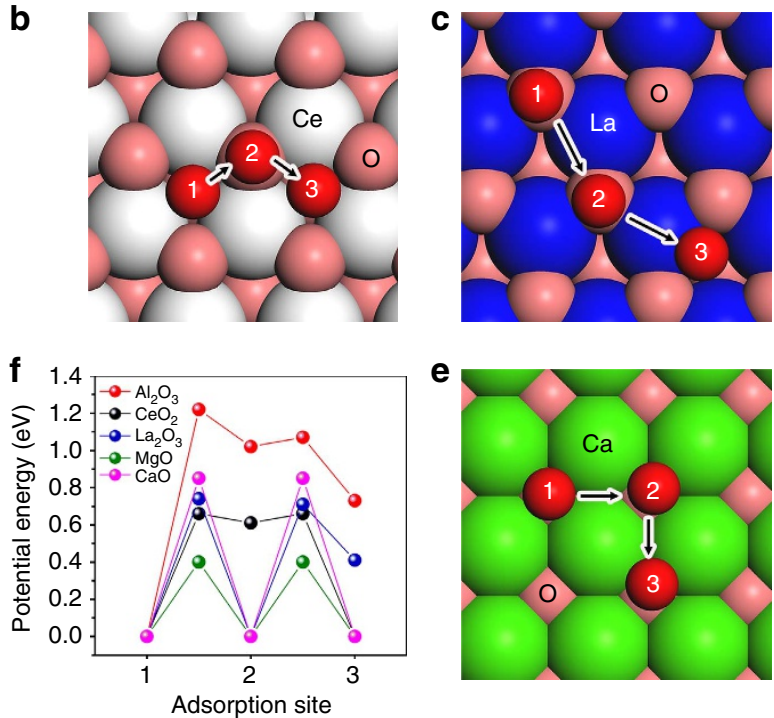

Figure 7 | Lithium diffusion mechanism on the surface of various metal oxides. (a-e) Minimum energy path for lithium ion diffusion on $\mathrm{Al}_{2} \mathrm{O}_{3}(110)$, $\mathrm{CeO}_{2}(111), \mathrm{La}_{2} \mathrm{O}_{3}(001), \mathrm{MgO}(100)$ and $\mathrm{CaO}(100)$ surfaces, respectively. (f) Potential energy profiles for $\mathrm{Li}^{+}$diffusion along different adsorption sites on the oxide surface. 
Because the first role of oxides is adsorption, the binding between the sulfides species and the matrix should be strong, which can both suppress the shuttle effect and enable the full utilization of active materials. Considering that the $\mathrm{Li}_{2} \mathrm{~S}_{x}$ capture is the monolayer chemisorption and the adsorption amount will depend on the surface area of oxides, uniformly distributed oxides nanostructures with high surface area are essential. Although strong binding and high surface area are preconditions, the surface diffusion properties of oxides are also very important, which affect the distribution and structure of $\mathrm{Li}_{2} \mathrm{~S}$. An optimized balance between $\mathrm{Li}_{2} \mathrm{~S}_{x}$ adsorption and surface diffusion is favourable for the sulfide species to deposit on the surface of oxide/carbon matrix, keep active during the cycling and ensure the final good cycling performance of batteries. In addition, some other factors such as electric conductivities, chemical stability and lithiation/delithiation of the oxides also need to be considered.

In conclusion, a series of nonconductive metal oxides $(\mathrm{MgO}$, $\mathrm{Al}_{2} \mathrm{O}_{3}, \mathrm{CeO}_{2}, \mathrm{La}_{2} \mathrm{O}_{3}$ and $\mathrm{CaO}$ ) nanoparticles anchored on porous carbon nanoflakes have been synthesized successfully via a facile and generic biotemplating method using Kapok trees fibres as both the template and the carbon source. The composite cathode materials based on the $\mathrm{MgO} / \mathrm{C}, \mathrm{La}_{2} \mathrm{O}_{3} / \mathrm{C}$ and $\mathrm{CeO}_{2} / \mathrm{C}$ nanoflakes show higher capacity and better cycling performance. Moreover, the working mechanisms of these oxides were revealed by adsorption test, microstructure analysis, electrochemical performance evaluation and DFT calculations. In addition, the comprehensive oxide selection criteria referring to the strong binding, high surface area and good surface diffusion properties were proposed for the first time. We believe that our proposed selection criteria can be generalized to other matrix materials for high performance Li-S batteries such as metal sulfides, metal nitrides, metal chlorides, and so on.

\section{Methods}

Preparation of metal oxide nanoparticles. A generic Pechini sol-gel method ${ }^{13}$ was used to synthesize the pure metal oxides. $0.01 \mathrm{~mol}$ metal nitrates of the desired metals were dissolved in $5 \mathrm{ml}$ of deionized water under stirring. $0.015 \mathrm{~mol}$ citric acid was then added in to the prepared solution to chelate the metal ions and heated to $200^{\circ} \mathrm{C}$ to form a dry and porous gel. After the calcination of the gel at $850^{\circ} \mathrm{C}$ for $1 \mathrm{~h}$, pure metal oxide $\left(\mathrm{Al}_{2} \mathrm{O}_{3}, \mathrm{CeO}_{2}, \mathrm{La}_{2} \mathrm{O}_{3}, \mathrm{MgO}\right.$ and $\left.\mathrm{CaO}\right)$ nanoparticles were obtained.

Biotemplated fabrication of metal oxide/carbon nanoflakes. Owing to the poor electric conductivity of $\mathrm{Al}_{2} \mathrm{O}_{3}, \mathrm{CeO}_{2}, \mathrm{La}_{2} \mathrm{O}_{3}, \mathrm{MgO}$ and $\mathrm{CaO}$, a series or metal oxide decorated porous carbon flakes were fabricated using the Kapok tree fibres as both the template and the carbon sources. To start with, $0.01 \mathrm{~mol}$ metal nitrates of the desired metals were dissolved in $40 \mathrm{ml}$ of deionized water to form transparent solution. Commercial Kapok tree fibre was washed with acetone and ethanol to remove the surface wax and dipped in to the nitrate solution. After $2 \mathrm{~h}$ soaking, the nitrate loaded fibres were separated from the solution and introduced into ammonia atmosphere to ensure the formation of the metal hydroxides, followed by the drying at $100^{\circ} \mathrm{C}$ for $10 \mathrm{~h}$ to remove the water. Then the dried fibres were inserted into the tube furnace and calcined at $850^{\circ} \mathrm{C}$ for $1 \mathrm{~h}$ with $100 \mathrm{sccm}$ continuous flow of argon. After cooling, the obtained carbon microtubes remaining the macromorphology of original Kapok tree fibres were easily grinded into carbon nanoflakes decorated with metal oxide nanoparticles.

Adsorption test. To prepare $\mathrm{Li}_{2} \mathrm{~S}_{8}$ solution, stoichiometric $\mathrm{Li}_{2} \mathrm{~S}$ and sulfur were dissolved in 1,3-dioxolane/1,2-dimethoxyethane solution (1:1 in volume) and stirred at $80^{\circ} \mathrm{C}$ for $24 \mathrm{~h}$. Then the $\mathrm{Li}_{2} \mathrm{~S}_{8}$ solution was diluted to $0.005 \mathrm{M}$ for the capture test. Before the adsorption test, all the oxide and oxide/carbon samples were dried under vacuum at $80^{\circ} \mathrm{C}$ for $24 \mathrm{~h}$. After the immersion of the samples in $0.005 \mathrm{M} \mathrm{Li}_{2} \mathrm{~S}_{8}$ at different temperatures, $20 \mu \mathrm{l}$ of the solution was transferred for the ICP-OES test ${ }^{45}$.

Characterization. The morphology and the microstructure were studied using SEM (FEI, XL30 Sirion) and TEM (FEI, Tecnai G2 F20 X-TWIN). The specific surface area was characterized from nitrogen adsorption-desorption measurement (Micromeritics, ASAP 2020). ICP-OES was conducted using a Thermo Scientific ICAP 6300 Duo View Spectrometer.
Electrochemical measurements. The sulfur cathode materials were prepared via a facile thermal diffusion method ${ }^{19}$. First, sulfur and grinded oxide/carbon nanoflakes with a weight ratio of 1:3 were mixed with appropriate amount of CS solution. After the evaporation of $\mathrm{CS}_{2}$, the mixture were pressed and heated at $155^{\circ} \mathrm{C}$ for $12 \mathrm{~h}$ under vacuum to obtain the composite cathode materials. To fabricate the 2,023 type coin cells for the electrochemical measurements, the synthesized composites were grinded again and mixed with conductive carbon black and polyvinylidene fluoride binder in N-methyl-2-pyrrolidinone (70:20:10 by weight) to form a slurry. After a $12 \mathrm{~h}$ magnetic stirring, the slurry was coated onto the aluminium foil and dried overnight at $60^{\circ} \mathrm{C}$ under vacuum. The sulfur content was in the range of $63-70 \mathrm{wt} \%$ and the mass loading of the electrodes ranges from 0.7 to $1.2 \mathrm{mg} \mathrm{cm}^{-2}$. $1 \mathrm{M}$ lithium bis(trifluoromethanesulphonyl)imide dissolved in a mixture of 1,3-dioxolaneand dimethoxymethane (1:1 by volume) with $0.1 \mathrm{M}$ $\mathrm{LiNO}_{3}$ additive was used as the electrolyte. Galvanostatic cycling was performed on Arbin or MTI testers with the potential range of $1.8-2.6 \mathrm{~V}$ versus $\mathrm{Li} / \mathrm{Li}^{+}$at ambient temperature.

DFT calculations. All calculations were performed using the Vienna ab initio Simulation Package code ${ }^{46}$ based on density functional theory. The projector augmented wave potentials were used to describe the interaction between ions and electrons ${ }^{47,48}$. Nonlocal exchange correlation energy was evaluated using the Perdew-Burke-Ernzehof functional. The electron wave function was expanded using plane waves with an energy cutoff of $400 \mathrm{eV}$. All structures were optimized with force convergence criterion of $10 \mathrm{meV}^{-1}$. All oxide surfaces were created based on the corresponding optimized bulk unit cell, which were in good agreement with the experimental values. A $4 \times 4 \times 1$ Monkhorst-Pack k-point mesh and a vacuum slab of about $15 \AA$ was inserted between the surface slabs for all the metal oxide models. The cell parameter is $8.40 \times 8.07 \times 25.00 \AA$ for $\mathrm{Al}_{2} \mathrm{O}_{3}(110)$, $11.67 \times 11.67 \times 22.94 \AA$ for $\mathrm{CeO}_{2}(111), 11.82 \times 11.82 \times 25.00 \AA$ for $\mathrm{La}_{2} \mathrm{O}_{3}(001)$, $8.99 \times 8.99 \times 20.00 \AA$ for $\mathrm{MgO}(100)$ and $10.25 \times 10.25 \times 20.00 \AA$ for $\mathrm{CaO}(100)$ DFT $+U$ approach, where $U$ is an empirical parameter for on site electronic correlations, was used in the calculation of $\mathrm{CeO}_{2}(111)$ with a $U$ value of $5.0 \mathrm{eV}$ (ref. 49). The adsorption energies $\left(E_{\mathrm{a}}\right)$ for $\mathrm{S}$ and $\mathrm{Li}_{2} \mathrm{~S}$ on the metal oxide surfaces are defined as $E_{\mathrm{a}}=E_{\text {total }}-E_{\text {ads }}-E_{\text {suf, where }} E_{\text {total }}$ is the total energy of the adsorbed system, $E_{\text {ads }}$ is the energy of the adsorbate in vacuum and $E_{\text {suf }}$ is the energy of the optimized clean surface slab.

\section{References}

1. Bruce, P. G., Freunberger, S. A., Hardwick, L. J. \& Tarascon, J. M. Li-O 2 and Li-S batteries with high energy storage. Nat. Mater. 11, 19-29 (2012).

2. Yamin, H., Gorenshtein, A., Penciner, J., Sternberg, Y. \& Peled, E. Lithium sulfur battery-oxidation reduction-mechanisms of polysulfides in the solutions. J. Electrochem. Soc. 135, 1045-1048 (1988).

3. Ji, X. L., Lee, K. T. \& Nazar, L. F. A highly ordered nanostructured carbonsulphur cathode for lithium-sulphur batteries. Nat. Mater. 8, 500-506 (2009).

4. Yao, H. B. et al. Improving lithium-sulphur batteries through spatial control of sulphur species deposition on a hybrid electrode surface. Nat. Commun. 5, 3943 (2014).

5. Su, Y. S. \& Manthiram, A. Lithium-sulphur batteries with a microporous carbon paper as a bifunctional interlayer. Nat. Commun. 3, 1166 (2012).

6. Seh, Z. W. et al. Sulphur- $\mathrm{TiO}_{2}$ yolk-shell nanoarchitecture with internal void space for long-cycle lithium-sulphur batteries. Nat. Commun. 4, 1331 (2013).

7. Guo, J. C., Xu, Y. H. \& Wang, C. S. Sulfur-impregnated disordered carbon nanotubes cathode for lithium-sulfur batteries. Nano Lett. 11, 4288-4294 (2011).

8. Demir-Cakan, R. et al. Li-S batteries: simple approaches for superior performance. Energy Environ. Sci. 6, 176-182 (2013).

9. Yang, Y., Zheng, G. Y. \& Cui, Y. Nanostructured sulfur cathodes. Chem. Soc. Rev. 42, 3018-3032 (2013).

10. Zhou, G. M. et al. A graphene-pure-sulfur sandwich structure for ultrafast, long-life lithium-sulfur batteries. Adv. Mater. 26, 625-631 (2014).

11. Kim, J. S., Hwang, T. H., Kim, B. G., Min, J. \& Choi, J. W. A lithium-sulfur battery with a high areal energy density. Adv. Funct. Mater. 24, 5359 (2014).

12. Zhang, Y. G., Zhao, Y., Yermukhambetova, A., Bakenov, Z. \& Chen, P. Ternary sulfur/polyacrylonitrile $/ \mathrm{Mg}_{0.6} \mathrm{Ni}_{0.4} \mathrm{O}$ composite cathodes for high performance lithium/sulfur batteries. J. Mater. Chem. A 1, 295-301 (2013).

13. Tao, X. Y. et al. Highly mesoporous carbon foams synthesized by a facile, costeffective and template-free Pechini method for advanced lithium-sulfur batteries. J. Mater. Chem. A 1, 3295-3301 (2013).

14. Zhou, G. M. et al. A flexible sulfur-graphene-polypropylene separator integrated electrode for advanced Li-S batteries. Adv. Mater. 27, 641-647 (2015).

15. Wang, J., He, Y.-S. \& Yang, J. Sulfur-based composite cathode materials for high-energy rechargeable lithium batteries. Adv. Mater. 27, 569-575 (2015)

16. Liang, X. et al. A highly efficient polysulfide mediator for lithium-sulfur batteries. Nat. Commun. 6, 5682 (2015).

17. Zhao, M.-Q. et al. Unstacked double-layer templated graphene for high-rate lithium-sulphur batteries. Nat. Commun. 5, 3410 (2014). 
18. Wang, Z. et al. Enhancing lithium-sulphur battery performance by strongly binding the discharge products on amino-functionalized reduced graphene oxide. Nat. Commun. 5, 5002 (2014).

19. Tao, X. Y. et al. Strong sulfur binding with conducting Magneli-phase $\mathrm{Ti}_{\mathrm{n}} \mathrm{O}_{2 \mathrm{n}-1}$ nanomaterials for improving lithium-sulfur batteries. Nano Lett. 14, 5288-5294 (2014).

20. Seh, Z. W. et al. Two-dimensional layered transition metal disulphides for effective encapsulation of high-capacity lithium sulphide cathodes. Nat. Commun. 5, 5017 (2014).

21. Qiu, Y. C. et al. High-rate, ultra long cycle-life lithium/sulfur batteries enabled by nitrogen-doped graphene. Nano Lett. 14, 4821-4827 (2014).

22. Huang, C. et al. Manipulating surface reactions in lithium-sulphur batteries using hybrid anode structures. Nat. Commun. 5, 3015 (2014).

23. Suo, L., Hu, Y.-S., Li, H., Armand, M. \& Chen, L. A new class of Solvent-in-Salt electrolyte for high-energy rechargeable metallic lithium batteries. Nat. Commun. 4, 1481 (2013).

24. Kim, H., Lee, J., Ahn, H., Kim, O. \& Park, M. J. Synthesis of threedimensionally interconnected sulfur-rich polymers for cathode materials of high-rate lithium-sulfur batteries. Nat. Commun. 6, 7278 (2015).

25. Chen, H. W. et al. Monodispersed sulfur nanoparticles for lithium sulfur batteries with theoretical performance. Nano Lett. 15, 798-802 (2015).

26. Chen, H. W. et al. Rational design of cathode structure for high rate performance lithium-sulfur batteries. Nano Lett. 15, 5443-5448 (2015).

27. Wang, B., Alhassan, S. M. \& Pantelides, S. T. Formation of large polysulfide complexes during the lithium-sulfur battery discharge. Phys. Rev. Appl. 2, 034004 (2014).

28. Mikhaylik, Y. V. \& Akridge, J. R. Polysulfide shuttle study in the Li/S battery system. J. Electrochem. Soc. 151, A1969-A1976 (2004).

29. Wang, H. L. et al. Graphene-wrapped sulfur particles as a rechargeable lithiumsulfur battery cathode material with high capacity and cycling stability. Nano Lett. 11, 2644-2647 (2011).

30. Yang, Y. et al. Improving the performance of lithium-sulfur batteries by conductive polymer coating. ACS Nano. 5, 9187-9193 (2011).

31. Tao, X. Y. et al. Decoration of sulfur with porous metal nanostructures: an alternative strategy for improving the cyclability of sulfur cathode materials for advanced lithium-sulfur batteries. Chem. Commun. 49, 4513-4515 (2013).

32. Cheon, S. E. et al. Rechargeable lithium sulfur battery-II. Rate capability and cycle characteristics. J. Electrochem. Soc. 150, A800-A805 (2003).

33. Yang, Y. et al. New nanostructured $\mathrm{Li}_{2} \mathrm{~S} /$ silicon rechargeable battery with high specific energy. Nano Lett. 10, 1486-1491 (2010).

34. Zheng, G. Y. et al. Amphiphilic surface modification of hollow carbon nanofibers for improved cycle life of lithium sulfur batteries. Nano Lett. 13, 1265-1270 (2013).

35. Li, W. Y. et al. Understanding the role of different conductive polymers in improving the nanostructured sulfur cathode performance. Nano Lett. 13, 5534-5540 (2013).

36. Zhou, W. D., Xiao, X. C., Cai, M. \& Yang, L. Polydopamine-coated, nitrogendoped, hollow carbon sulfur double-layered core-shell structure for improving lithium sulfur batteries. Nano Lett. 14, 5250-5256 (2014).

37. Wang, C. et al. Macroporous free-standing nano-sulfur/reduced graphene oxide paper as stable cathode for lithium-sulfur battery. Nano Energy 11, 678-686 (2015).

38. Zhou, G. M., Paek, E., Hwang, G. S. \& Manthiram, A. Long-life Li/polysulphide batteries with high sulphur loading enabled by lightweight three-dimensional nitrogen/sulphur-codoped graphene sponge. Nat. Commun. 6, 7760 (2015)

39. Zheng, J. M. et al. Lewis acid-base interactions between polysulfides and metal organic framework in lithium sulfur batteries. Nano Lett. 14, 2345-2352 (2014).

40. Zhou, G. M., Zhao, Y. B. \& Manthiram, A. Dual-confined flexible sulfur cathodes encapsulated in nitrogen-doped double-shelled hollow carbon spheres and wrapped with graphene for Li-S batteries. Adv. Energy Mater. 5, 1402263 (2015).
41. Dong, K., Wang, S. P., Zhang, H. Y. \& Wu, J. P. Preparation and electrochemical performance of sulfur-alumina cathode material for lithium-sulfur batteries. Mater. Res. Bull. 48, 2079-2083 (2013).

42. Sun, F. G. et al. A high-rate lithium-sulfur battery assisted by nitrogen-enriched mesoporous carbons decorated with ultrafine $\mathrm{La}_{2} \mathrm{O}_{3}$ nanoparticles. J. Mater. Chem. A 1, 13283-13289 (2013).

43. Chaiarrekij, S., Apirakchaiskul, A., Suvarnakich, K. \& Kiatkamjornwong, S. Kapok I: characteristcs of Kapok fiber as a potential pulp source for papermaking. Bioresources 7, 475-488 (2012).

44. Li, P. et al. Lithium sodium vanadium phosphate and its phase transition as cathode material for lithium ion batteries. Electrochim. Acta 180, 120-128 (2015).

45. Diao, Y., Xie, K., Xiong, S. \& Hong, X. Analysis of polysulfide dissolved in electrolyte in discharge-charge process of Li-S battery. J. Electrochem. Soc. 159, A421-A425 (2012).

46. Kresse, G. \& Furthmuller, J. Efficiency of ab-initio total energy calculations for metals and semiconductors using a plane-wave basis set. Comput. Mater. Sci. 6, 15-50 (1996)

47. Blochl, P. E. Projector augmented-wave method. Phys. Rev. B 50, 17953-17979 (1994).

48. Kresse, G. \& Joubert, D. From ultrasoft pseudopotentials to the projector augmented-wave method. Phys. Rev. B 59, 1758-1775 (1999).

49. Nolan, M., Parker, S. C. \& Watson, G. W. The electronic structure of oxygen vacancy defects at the low index surfaces of ceria. Surf. Sci. 595, 223-232 (2005).

\section{Acknowledgements}

Y.C. acknowledges the support from the Assistant Secretary for Energy Efficiency and Renewable Energy, Office of Vehicle Technologies of the US Department of Energy under the Battery Materials Research (BMR) Program. X.Y.T. and J.G.W. acknowledge support from the Natural Science Foundation of Zhejiang Province (grants LR13E020002) and the National Natural Science Foundation of China (51002138 and 21136001).

\section{Author contributions}

Y.C. and X.Y.T. conceived the idea. X.Y.T. designed the experiments, synthesized the materials and performed electrochemical test. J.G.W. and Q.X.C. carried out the DFT calculation and analyzed the result. C.L., H.T.W., G.Y.Z. and other authors conducted materials characterization. All authors discussed the electrochemical results and the whole paper.

\section{Additional information}

Supplementary Information accompanies this paper at http://www.nature.com/ naturecommunications

Competing financial interests: The authors declare no competing financial interests.

Reprints and permission information is available online at http://npg.nature.com/ reprintsandpermissions/

How to cite this article: Tao, X. Y. et al. Balancing surface adsorption and diffusion of lithium-polysulfides on nonconductive oxides for lithium-sulfur battery design. Nat. Commun. 7:11203 doi: 10.1038/ncomms11203 (2016).

This work is licensed under a Creative Commons Attribution 4.0 International License. The images or other third party material in this article are included in the article's Creative Commons license, unless indicated otherwise in the credit line; if the material is not included under the Creative Commons license, users will need to obtain permission from the license holder to reproduce the material. To view a copy of this license, visit http://creativecommons.org/licenses/by/4.0/ 